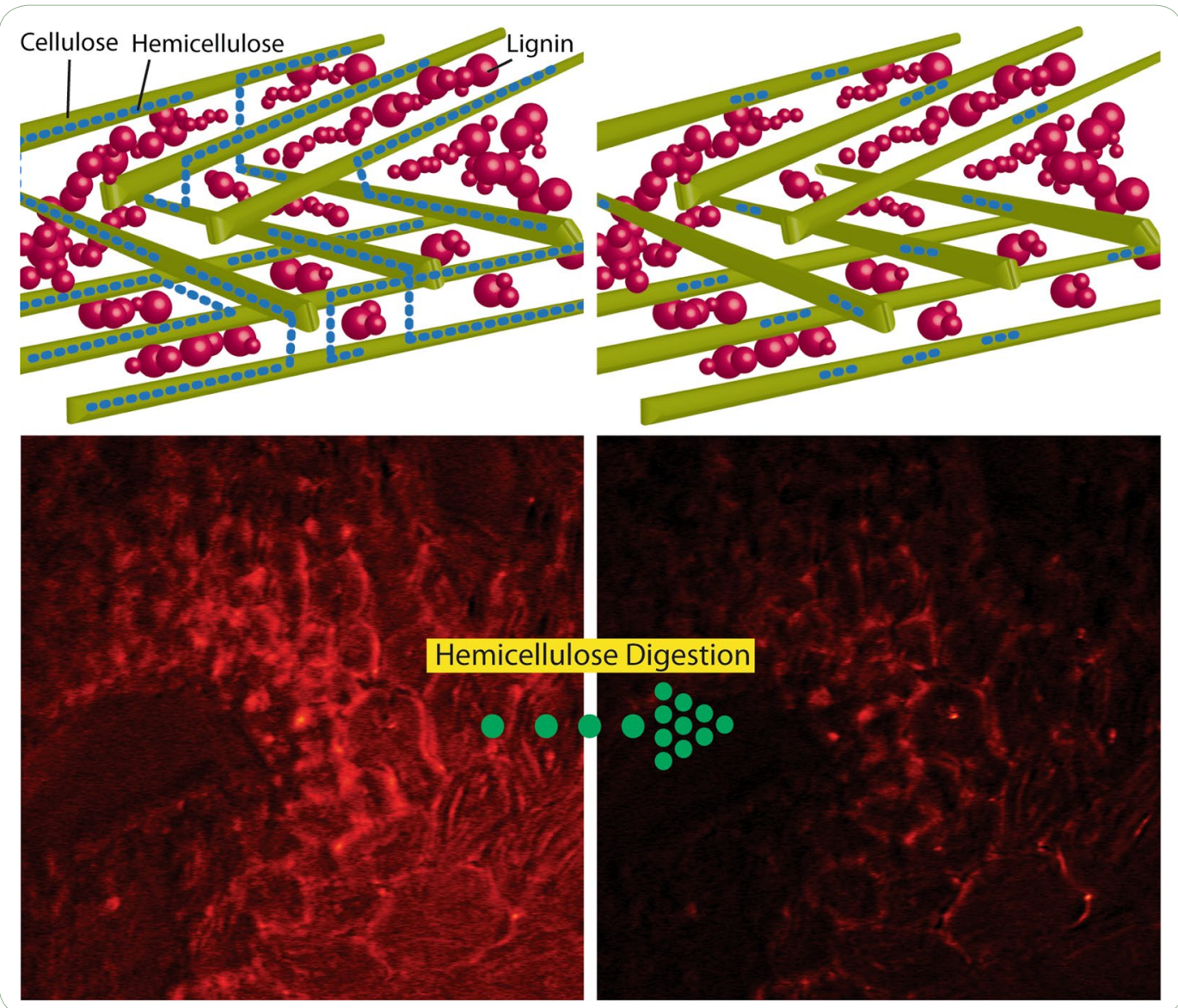

\title{
In situ label-free imaging of hemicellulose in plant cell walls using stimulated Raman scattering microscopy
}

Zeng et al.

() Biomed Central 


\title{
In situ label-free imaging of hemicellulose in plant cell walls using stimulated Raman scattering microscopy
}

\author{
Yining Zeng ${ }^{1,3^{*}}$, John M. Yarbrough ${ }^{1,3}$, Ashutosh Mittal ${ }^{1}$, Melvin P. Tucker ${ }^{2,3}$, Todd B. Vinzant ${ }^{1}$, \\ Stephen R. Decker ${ }^{1,3}$ and Michael E. Himmel ${ }^{1,3^{*}}$
}

\begin{abstract}
Background: Plant hemicellulose (largely xylan) is an excellent feedstock for renewable energy production and second only to cellulose in abundance. Beyond a source of fermentable sugars, xylan constitutes a critical polymer in the plant cell wall, where its precise role in wall assembly, maturation, and deconstruction remains primarily hypothetical. Effective detection of xylan, particularly by in situ imaging of xylan in the presence of other biopolymers, would provide critical information for tackling the challenges of understanding the assembly and enhancing the liberation of xylan from plant materials.
\end{abstract}

Results: Raman-based imaging techniques, especially the highly sensitive stimulated Raman scattering (SRS) microscopy, have proven to be valuable tools for label-free imaging. However, due to the complex nature of plant materials, especially those same chemical groups shared between xylan and cellulose, the utility of specific Raman vibrational modes that are unique to xylan have been debated. Here, we report a novel approach based on combining spectroscopic analysis and chemical/enzymatic xylan removal from corn stover cell walls, to make progress in meeting this analytical challenge. We have identified several Raman peaks associated with xylan content in cell walls for label-free in situ imaging xylan in plant cell wall.

Conclusion: We demonstrated that xylan can be resolved from cellulose and lignin in situ using enzymatic digestion and label-free SRS microscopy in both 2D and 3D. We believe that this novel approach can be used to map xylan in plant cell walls and that this ability will enhance our understanding of the role played by xylan in cell wall biosynthesis and deconstruction.

Keywords: Hemicellulose, Xylan, Xylanase, Label-free imaging, Raman Spectroscopy, Stimulated Raman Scattering (SRS), Microscopy

\section{Background}

Hemicellulose plays a critical role in plant cell wall assembly, maturation, and deconstruction, particularly in grass and secondary walls of woody plants. As an important resource biopolymer, xylan is widely available from various sources, such as energy crop biomass, where it represents $22 \%$ of corn stover and other grass agriculture residues [1]; and can be relatively easily extracted [2]. In

\footnotetext{
*Correspondence: Yining.Zeng@nrel.gov; Mike.Himmel@nrel.gov ${ }^{1}$ Biosciences Center, National Renewable Energy Laboratory, Golden, CO 80401, USA

Full list of author information is available at the end of the article
}

the search for more efficient strategies to convert biomass to fuels and high-value chemicals, xylan represents unique challenges and opportunities. In the process of conversion of biomass to drop-in biofuels, xylan is both a significant sugar source for biofuels fermentation and yet, also a factor contributing to biomass recalcitrance. The fermentation of xylan also produces xylitol, a lowcaloric sweetener and an agent against dental caries with huge marketability in the food industry and with clinical applications [3]. Xylo-oligosaccharides derived from xylan are widely used in food and health products as bioactive ingredients [4-10]. With proper cross-linking 
chemistries, xylan can form porous forms and gels [11]. The bio-derived and biocompatible foamy materials derived from xylan also have key roles in numerous non-fuel market sectors, including cosmetics, drug delivery, tissue engineering, insulation, and gas storage [12]. Sugar-based non-ionic surfactants produced from xylan have also attracted growing attention due to their biodegradability and excellent foaming properties [13]. With the advent of engineered biomaterials, such as cellulose nano-fibers, cellulose nanocrystals, chitosans, and polyvinyl alcohol polymers, xylan can be considered another polymer suitable for renewable and biodegradable films that are more economical than those made from oilbased polymers [14]. Because of numerous applications for xylan, extensive research has been conducted to develop chemical and biological approaches to effectively separate xylan from the rest of lignocellulose with high sugar yields. In the past, attempts have also been made to in situ modify the xylan in the plant cell wall to produce xylan derivatives [15-17]. Effective detection of xylan, particularly in situ imaging of xylan in the presence of other biopolymers, would provide new tools to study the assembly and liberation of xylan from plant materials.

Wet laboratory methodologies have been used in the past to provide accurate qualitative and quantitative measurements of carbohydrates. Depending on the nature of the samples under study, these analyses may involve specialized sample preparation steps to extract, hydrolyze, and remove moisture before chromatographic and/or spectroscopic analysis. Therefore, fast and nondestructive analytical techniques are needed. Infrared spectroscopy has been used to estimate the concentration of methoxyl and acetyl groups on xylan [18] and has been applied to corn stover, poplar, and spruce samples to analyze changes that are caused by various thermal chemical pretreatments $[19,20]$. Near infrared spectroscopy combined with multivariate analytical statistical methods has also been used to assess the chemical composition of corn stover and switchgrass [21,22] wood [23] and Kraft pulps [24]. In the past, we have also applied non-linear Raman microscopic techniques, such as coherent antiStokes Raman scattering (CARS) and stimulated Raman scattering (SRS) microscopies, to obtain high-resolution $(\sim 300 \mathrm{~nm})$, chemically specific, and non-destructive imaging information regarding the distribution of important chemical compositions in the plant cell wall [2529]. While the non-linear Raman techniques rely on the Raman activity of a specific chemical group, they provide signal intensity of orders of magnitude higher than spontaneous Raman microscopy, offering much faster imaging acquisition rates [26].

Raman spectra of plant cell walls contain the vibrational modes primarily from three major wall components: lignin, cellulose, and hemicellulose (mostly xylan). Besides some relatively weak peaks, lignin's primary Raman contribution is located around $1600 \mathrm{~cm}^{-1}$. Cellulose has broad Raman contributions; however, the peaks around $1100 \mathrm{~cm}^{-1}$ are widely considered as the unique Raman peak for cellulose. In the past, 1100 and $1600 \mathrm{~cm}^{-1}$ have been chosen by most of the Raman imaging efforts to in situ map cellulose and lignin in plant cell walls [26, 30-33]. Conversely, in situ mapping of xylan using Raman imaging is not common. One key challenge is that xylan and cellulose have similar chemical groups. Cellulose is a linear homopolymer consisting of glucose residues linked together by $\beta-1,4$-glycosidic bonds. Due to the inter- and intra-chain hydrogen bonds, the structure of cellulose is highly ordered. There have been six different crystalline forms of cellulose reported: cellulose I, II, III $, \mathrm{III}_{\mathrm{II}}, \mathrm{IV}_{\mathrm{I}}$, and $\mathrm{IV}_{\mathrm{II}}$. Cellulose I and II are found in nature and the other allomorphs can be obtained by chemical or physical treatments [34]. Cellulose I is the main form of cellulose consisting of two allomorphs: cellulose I $\alpha$ and I $\beta$, which differ by the hydrogen patterns (Additional file 1: Fig. S1). The inter-chain hydrogen bond $\mathrm{O} 6-\mathrm{H}-\mathrm{O} 3$ is dominant in cellulose I, whereas in cellulose II, the $\mathrm{O} 6-\mathrm{H}-\mathrm{O} 2$ is dominant. In cellulose I and II, the $\mathrm{O} 3-\mathrm{H}-\mathrm{O} 5$ intra-chain hydrogen bonds make each cellulose chain rigid and linear in shape. In contrast, xylan in the plant cell wall has a variety of side chains attached to the linear $\beta-1,4$-xylopyranose backbone, forming an amorphous structure [35] (Additional file 1: Fig. S1). Besides the difference in the chemical composition of the backbone sugar units and the sidechains, cellulose and xylan have dramatically different organizations of chemical backbones, which could affect their Raman spectra. It has already been discovered that a Raman peak in the spectrum may contain contribution not only from a single chemical group, but from a composite of several interacting vibrational motions involving multiple sites in the molecule [36, 37]. A good example of this case is the Raman spectra from cellulose I and II: although they have exactly the same chemical groups and bonding, their different cellulose chain organizations lead to two different spectra [38].

Over the past few years, extensive effort has been devoted to distinguish Raman contributions of xylan from the rest of cell wall components; however, the results varied depending on the materials chosen for study and the separation methods used to extract the samples [39, 40]. By using extracted hemicelluloses from woody materials, hemicellulose was found to contribute broadly to the Raman spectrum, which made hemicellulose difficult to distinguish by Raman alone [39]. A combination of principle component analysis and multivariate curve resolution applied to the Raman 
spectroscopy of isolated cell wall polysaccharides suggested that the Raman peaks from hemicellulose overlapped with those of cellulose. However, in the cell wall, this result might be also explained by the possibility that hemicellulose is distributed homogenously with cellulose [41]. In flax fibers, it was suggested that the weak Raman peaks at $800-870$ and $475-515 \mathrm{~cm}^{-1}$ can potentially be used to identify xylan [42]. Chu et al. reported that in Miscanthus the weak Raman peak at $478 \mathrm{~cm}^{-1}$ was related to the $\mathrm{HCC}$ and $\mathrm{HCO}$ bending of the $\mathrm{C} 6$ group in hemicellulose [43].

Due to the complex nature of the biomass substrate, separation of xylan from the rest of cell wall components seems to be inevitable for accurate xylan quantification. However, common chemical approaches create broad impacts for all the cell wall components. Here, we report an approach to use xylanases to specifically digest large portions of xylan in a carefully pretreated corn stover substrate. No detectable lignin or cellulose was digested by the assay. This approach allowed us to produce a series of artificial xylan "concentration ladders" in corn stover substrates. By comparing the Raman spectra from xylan model compounds obtained from different sources and with different degrees of polymerization, we determined several Raman bands that are sensitive to xylan and demonstrated that xylan in corn stover cell walls can be imaged at surprising detail.

\section{Results and discussion}

\section{Raman spectral analysis reveals potential xylan-specific bands}

Figure 1 (top row) shows the Raman spectrum from the undigested deacetylated corn stover control containing $31 \%$ of xylan, as well as cellulose and lignin (Table 1). After xylanase digestion, $55 \%$ of the cell wall xylan was removed (the resulting Raman spectrum is also shown in Fig. 1). The Raman spectra from the xylan model compounds obtained from various sources, with more than 68\% xylan content (Table 1), are also listed in Fig. 1 for comparison. Those xylan model compounds have a wide range of degrees of polymerization (DP) from D-xylose

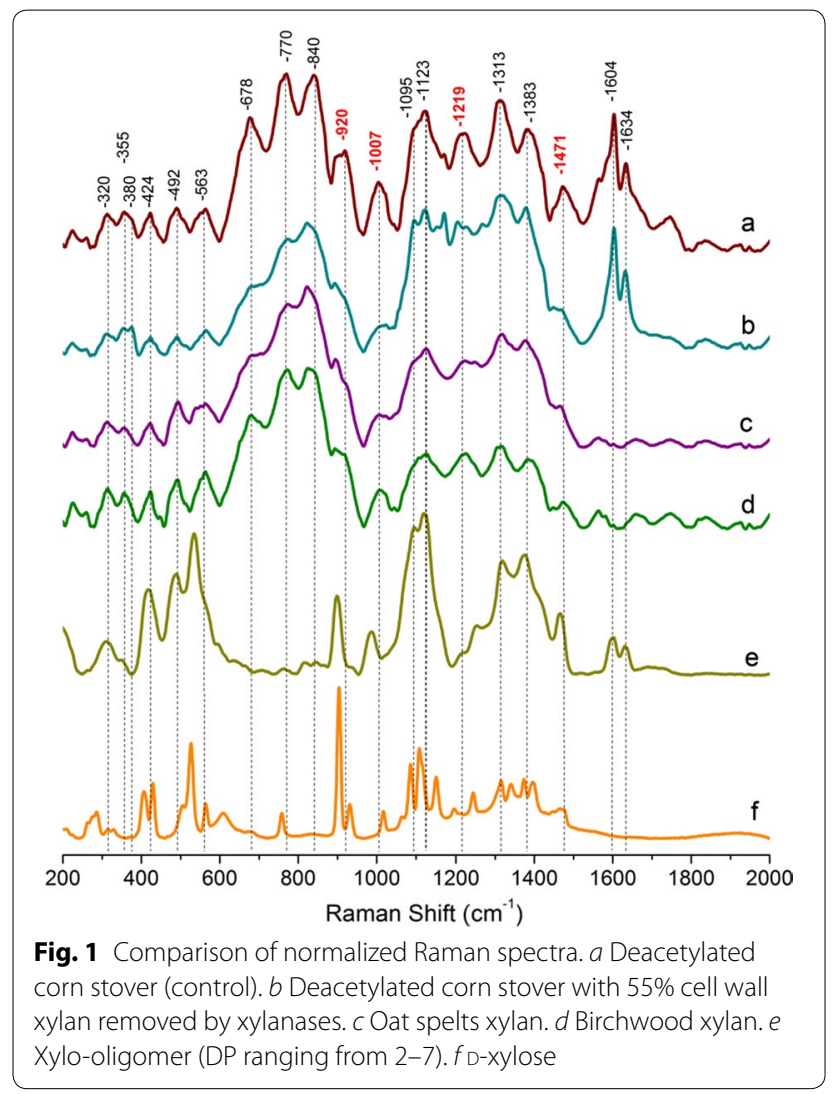

monomer to short oligomers with DP 2-7; as well as extracted xylan polymers with DP100-200.

Starting from the low frequency end, previous normal coordinate calculations revealed that the $250-600 \mathrm{~cm}^{-1}$ Raman region mainly contains the vibrational contributions from the skeleton bending involving $\mathrm{CCC}, \mathrm{COC}$, OCC, and OCO [44]. There are also small contributions from methine bending $(\mathrm{CCH}$ and $\mathrm{OCH})$ and skeletal stretching (CC and $\mathrm{CO}$ ) in this region [44]. Previous Raman spectroscopy studies of Valonia and Ramie cellulose found that the 320,355 , and $380 \mathrm{~cm}^{-1}$ peaks are associated with heavy atom bending [36, 44]. A Raman microscopy investigation of the tomato cell wall

Table 1 Chemical compositional analysis (Wt\%) of deacetylated corn stover control and extracted xylan models

\begin{tabular}{|c|c|c|c|c|c|c|c|c|c|}
\hline Sample & Glucan \% & Xylan \% & Lignin \% & Galactan \% & Arabinan \% & Fructan \% & Mannan \% & Acetate \% & Total \% \\
\hline Deacetylated corn stover & $45 \pm 3$ & $31 \pm 2$ & $13 \pm 2$ & $1.8 \pm 0.5$ & $1.7 \pm 0.5$ & $0.0 \pm 0.1$ & $0.0 \pm 0.1$ & $0.2 \pm 0.1$ & 93 \\
\hline $\begin{array}{l}\text { Deacetylated corn stover with } 55 \% \\
\text { cell wall xylan removed by xylanases }\end{array}$ & $66 \pm 4$ & $12 \pm 2$ & $18 \pm 2$ & $1.0 \pm 0.2$ & $1.0 \pm 0.2$ & $0.3 \pm 0.1$ & $0.0 \pm 0.1$ & $0.1 \pm 0.1$ & 98 \\
\hline Xylo-oligo DP2-7 & $12 \pm 2$ & $73 \pm 4$ & $5 \pm 2$ & $3.4 \pm 0.5$ & $3.1 \pm 0.5$ & $0.0 \pm 0.1$ & $0.0 \pm 0.1$ & $1.6 \pm 0.5$ & 98 \\
\hline Oat spelts xylan & $6 \pm 1$ & $68 \pm 4$ & $3 \pm 1$ & $1.0 \pm 0.2$ & $6 \pm 1$ & $0.0 \pm 0.1$ & $0.0 \pm 0.1$ & $5 \pm 1$ & 89 \\
\hline Birchwood xylan & $1 \pm 1$ & $80 \pm 5$ & $2 \pm 1$ & $0.3 \pm 0.1$ & $0.5 \pm 0.1$ & $0.0 \pm 0.1$ & $0.00 \pm 0.1$ & $0.0 \pm 0.1$ & 84 \\
\hline
\end{tabular}

Oat spelts and birchwood xylan samples also contain 3-4\% and $10-12 \%$ glucuronic acid 
suggested that the $380 \mathrm{~cm}^{-1}$ peak belongs to $\delta(C C C)$ ring vibration from the cellulose [41]. Polarization Raman spectroscopy of the orientation of the chemical groups of cellulose indicated that the $320 \mathrm{~cm}^{-1}$ peak is associated with $\delta(\mathrm{CCC})$ ring vibration motions that are parallel to the cellulose chain axis [32], and that the 355 and $380 \mathrm{~cm}^{-1}$ peaks contain vibration motions both parallel and perpendicular to the cellulose chain axis [36, 37]. In the present study, after about $55 \%$ of cell wall xylan was hydrolyzed by enzymes, the 320,355 , and $380 \mathrm{~cm}^{-1}$ peaks showed very small changes. This observation indicates these three peaks are likely not directly linked to xylanase accessible xylan.

The 424, 492, and $563 \mathrm{~cm}^{-1}$ peaks appear in the deacetylated corn stover, the deacetylated corn stover following 55\% xylan removal and the xylan model compounds. The $424 \mathrm{~cm}^{-1}$ peak was previously reported as $\delta(C C C)$ and $\delta(\mathrm{CCO})$ ring deformation in cellulose [38]. The $492 \mathrm{~cm}^{-1}$ peak is from cellulose glycosidic $v(C O C)$ vibration $[32,42]$. The $563 \mathrm{~cm}^{-1}$ peak was previously assigned to the cellulose $\delta(\mathrm{COC})$ ring vibration [38]. It seems, therefore, that the vibrations for 424,492 , and $563 \mathrm{~cm}^{-1}$ peaks could also exist in xylan. In fact, the Raman spectrum of the deacetylated corn stover sample with 55\% xylan removed shows that these peaks are only slightly affected by xylanase digestion, indicating that they do contain some contribution from xylan. The 424, 492, and $563 \mathrm{~cm}^{-1}$ peaks also appear in the xylo-oligomers DP27 , in which the $424 \mathrm{~cm}^{-1}$ and the $563 \mathrm{~cm}^{-1}$ peaks shift slightly to lower frequencies. In D-xylose, the $492 \mathrm{~cm}^{-1}$ glycosidic $v(\mathrm{COC})$ disappears, due to lack of any glycosidic bond and the $424 \mathrm{~cm}^{-1}$ ring deformation appears to degenerate into two peaks: the $407 \mathrm{~cm}^{-1}$ peak (ring bend coupled with $\mathrm{OH}$ bend) and the $433 \mathrm{~cm}^{-1}$ peak (ring deformation) [45]. It seems that in biomass, both cellulose and xylan contribute to the 424, 492, and $563 \mathrm{~cm}^{-1}$ bands. Enzymatic digestion of xylan alone from cell walls, therefore, should affect their peak intensity slightly.

The 678,770 , and $840 \mathrm{~cm}^{-1}$ peaks appear in the deacetylated corn stover control, the deacetylated corn stover sample with $55 \%$ xylan removed, oat spelts xylan, and birchwood xylan. Previously, it was reported that the $678 \mathrm{~cm}^{-1}$ peak was due to the low-frequency vibrations of the pyranoid rings [46]. In deacetylated corn stovers (Fig. 1a, b), the $770 \mathrm{~cm}^{-1}$ peak could be related to xyloglucan [47], and possibly some contribution from lignin aromatic rings, their substituent groups and side chains $[39,48]$ or ferulic acid attached to xylan. In oat spelts and birchwood (Fig. 1c, d), the $770 \mathrm{~cm}^{-1}$ band could be due to glucuronic acid group attached to xylan [49]. The Raman bands in the $830-900 \mathrm{~cm}^{-1}$ region have been related to the anomeric configuration of carbohydrates [46, 50-52].
The broad peak centered at 920 and the $1007 \mathrm{~cm}^{-1}$ peak found in the deacetylated corn stover control also appear in all of the xylan model compounds. For example, in D-xylose, there is a very strong peak at $900 \mathrm{~cm}^{-1}$ (symmetric COC str coupled with CC ring str) and a weak side peak at $930 \mathrm{~cm}^{-1}$ (the $\mathrm{CO}$ and the $\mathrm{CC}$ stretch coupled with methine deformation) [45]. The $900 \mathrm{~cm}^{-1}$ peak remains strong in the xylooligmers (DP2-7). In the oat spelts xylan, birchwood xylan, and deacetylated corn stover samples, this peak could be slightly overlapped with the lignin peak at $920-930 \mathrm{~cm}^{-1}$ (lignin skeletal deformation of aromatic rings, substituent groups, side chains, and $\mathrm{CCH}$ wag) [53]. The cellulose COC symmetric stretch also contributes to the $900 \mathrm{~cm}^{-1}$ [32]. After xylan removal, the $920 \mathrm{~cm}^{-1}$ peak is significantly reduced. It seems that this peak is associated with xylan, possibly COC stretch coupled with CC ring stretch. The D-xylose also has a medium strong peak at $1015 \mathrm{~cm}^{-1}$ due to $\mathrm{CC}$ and $\mathrm{CO}$ ring stretch coupled with methine deformation [45]. All the other xylan model polymers show a peak around $1007 \mathrm{~cm}^{-1}$ due to the $v(C-C)$ and $v(\mathrm{C}-\mathrm{OH})$ vibrations [40]. The $1007 \mathrm{~cm}^{-1}$ in deacetylated corn stover is significantly reduced when xylan is digested, indicating that it is associated with xylan, possibly via the $v(\mathrm{C}-\mathrm{C})$ and $v(\mathrm{C}-\mathrm{OH})$.

Both the 1095 and $1123 \mathrm{~cm}^{-1}$ peaks have traditionally been assigned to cellulose for its COC stretch and COC stretch plus ring breathing, respectively. It is known that xylan and glucomannan have a very small contribution to these peaks [39]. In the past, the 1095 and $1123 \mathrm{~cm}^{-1}$ peaks have been widely used to image cellulose content in the cell wall [25, 26, 30-32, 54]. As shown in Fig. 1, both of the peaks showed little change after enzymatic digestion of the xylan, indicating that the enzyme has minimal impact on cellulose.

The $1219 \mathrm{~cm}^{-1}$ peak in the deacetylated corn stover control also shows up in all the xylan model compounds. In D-xylose, the $1219 \mathrm{~cm}^{-1}$ peak shifts to $1246 \mathrm{~cm}^{-1}$, which has been reported as the methine deformation coupled with $\mathrm{OH}$ in-plane bend in D-xylose [45]. In the xylo-oligomer (DP2-7), it appears as a similar peak around $1246 \mathrm{~cm}^{-1}$, possibly due to the $\mathrm{C}-\mathrm{O}$ stretch, $\delta(\mathrm{CH})$ and/or $\delta(\mathrm{COH})$ in hemicellulose [39, 41, 55-57]. Some acetyl groups present on hemicellulose were also believed to contribute to the $1250 \mathrm{~cm}^{-1}$ peak $[57,58]$. The $1219 \mathrm{~cm}^{-1}$ peak is greatly affected when the cell wall xylan is solubilized by enzymes, confirming that this peak is closely related to xylan, possibly associated with the $\mathrm{COH}$ and $\mathrm{CH}$ groups of xylan.

The $\delta(\mathrm{CH})$ and $\delta(\mathrm{COH})$ vibrations of xylan contribute to the $1313 \mathrm{~cm}^{-1}$ found in the deacetylated corn stover control $[39,40]$. Some studies have specifically assigned 
the $1313 \mathrm{~cm}^{-1}$ peak to the $\mathrm{C} 3-\mathrm{OH}$ vibration on xylan [40]. In D-xylose, the $1313 \mathrm{~cm}^{-1}$ peak is associated with anomeric methine deformation coupled with $\mathrm{OH}$ inplane bend, and the $1340 \mathrm{~cm}^{-1}$ peak is associated with methine deformation coupled with methylene wag [45]. Besides xylan however, cellulose also contributes significantly to $1318-1335 \mathrm{~cm}^{-1}$ by $\omega\left(\mathrm{CH}_{2}\right), \delta(\mathrm{HCC}), \delta(\mathrm{HCO})$, and $\delta(\mathrm{COH})$ vibrations $[32,38]$. It has been reported that lignin also contributes in the region $1297-1334 \mathrm{~cm}^{-1}$, possibly due to its aliphatic $\mathrm{O}-\mathrm{H}$ bend vibration $[39,48]$ or vibration modes from $\mathrm{S}$ lignin [33]. The $1313 \mathrm{~cm}^{-1}$ peak is only partially reduced when xylan is enzymatically digested, confirming that it has partial contribution from xylan. The $1383 \mathrm{~cm}^{-1}$ peak in xylan could be due to the $\delta(\mathrm{CH})$ and $\delta(\mathrm{OH})$ vibration which were previously recorded at $1376 \mathrm{~cm}^{-1}$ [40]. In the deacetylated corn stover, oat spelts xylan, and birchwood xylan samples studied, it is likely that the $1383 \mathrm{~cm}^{-1}$ peak is also partly overlapped with the lignin peaks $1363 \mathrm{~cm}^{-1}$ and $1393 \mathrm{~cm}^{-1}$ from the $\mathrm{C}-\mathrm{H}$ bend in the $\mathrm{R}_{3} \mathrm{C}-\mathrm{H}$ and the phenolic $\mathrm{O}-\mathrm{H}$ bend in the lignin, respectively [39, 53]. Besides this, cellulose also contributes strongly to $1380 \mathrm{~cm}^{-1}$ with its $\delta(\mathrm{CH} 2), \delta(\mathrm{HCC}), \delta(\mathrm{HCO})$, and $\delta(\mathrm{COH})$ vibrations $[38,39]$. The $1383 \mathrm{~cm}^{-1}$ peak thus has little diagnostic value. The $1313 \mathrm{~cm}^{-1}$ peak is only partially affected by enzymatic xylan removal, indicating that it involves only partial Raman contributions from xylan.

The $1471 \mathrm{~cm}^{-1}$ peak was found in deacetylated corn stover samples and in all the xylan models including the monomer D-xylose. Previously, Raman studies on xylose have shown that the peak $1471 \mathrm{~cm}^{-1}$ is due to the $\mathrm{OH}$ in-plane bend coupled with the methine deformation $\left(1455 \mathrm{~cm}^{-1}\right)$ and the methylene scissors coupled with the wag vibration $\left(1480 \mathrm{~cm}^{-1}\right)$ [45]. In the Raman studies of black spruce, the $1471 \mathrm{~cm}^{-1}$ peak was also considered for xylan [39]. By comparing the Raman spectrum of deacetylated corn stover before and after enzymatic xylan removal, the $1471 \mathrm{~cm}^{-1}$ peak exhibits significant drop when the cell wall xylan content is solubilized, indicating that it is highly associated with xylan and possibly related to the $\mathrm{OH}$ and $\mathrm{CH}_{2}$ vibrations in xylan.

The two peaks at 1604 and $1634 \mathrm{~cm}^{-1}$ are the signature peaks known for lignin. Specifically, the $1604 \mathrm{~cm}^{-1}$ peak is due to the aromatic ring vibration, and the $1634 \mathrm{~cm}^{-1}$ is assigned to the $\mathrm{C}=\mathrm{C}$ stretch in the coniferaldehyde unit of lignin [59-62]. As shown in Fig. 1, both of the peaks showed little change after xylan digestion, indicating that the enzyme digestion has minimal impact on lignin.

\section{Xylan-content cell wall ladder confirms xylan-specific Raman bands}

In the above discussions (also summarized in Table 2), it was found that the Raman bands at 920, 1007, 1219, and
$1471 \mathrm{~cm}^{-1}$ are sensitive to cell wall xylan. To verify their dependence on xylan content, a series of deacetylated corn stover cell wall samples with relative xylan contents ranging from 45 to $100 \%$ (100\% for native cell wall xylan content) was created (Additional file 1: Table S1, S2). No lignin or cellulose solubilization was detected by compositional analysis (Additional file 1: Table S1).

Figure 2 shows the comparison of the lignin-specific Raman band at $1600 \mathrm{~cm}^{-1}$ from the deacetylated corn stover cell wall samples with various xylan contents. The error bars in each spectrum show the standard deviation of hundreds of spectrum scans. All the spectra are normalized by the $1604 \mathrm{~cm}^{-1}$ peak for comparison (baseline leveled at $\left.1520 \mathrm{~cm}^{-1}\right)$. Although the xylan content varies significantly, the lignin peaks are almost identical in the range from 1520 to $1700 \mathrm{~cm}^{-1}$. The peak height of the $1634 \mathrm{~cm}^{-1}$ peak is almost identical for both the control and the enzyme-digested deacetylated corn stover. The peak ratio of 1604 to $1634 \mathrm{~cm}^{-1}$ (Fig. 2, inset), reflecting relative contributions from the aromatic ring vibration versus the $\mathrm{C}=\mathrm{C}$ stretch in the coniferaldehyde unit of lignin, is constant for all the xylan concentrations. This implies that the ratio of coniferyl units and aromatic rings is constant.

Figure 3 shows the comparison of cellulose-specific Raman bands from the deacetylated corn stover control and the cell wall samples with altered xylan contents. For comparison, these spectra are normalized by the lignin peak at $1604 \mathrm{~cm}^{-1}$. The two cellulose signature peaks, 1095 and $1123 \mathrm{~cm}^{-1}$, show similar shape for all the samples, albeit with significantly different xylan content (Fig. 3a). The peak heights of 1095 and $1123 \mathrm{~cm}^{-1}$ (baseline at $1050 \mathrm{~cm}^{-1}$ ) remain the same for the control and the enzyme-digested deacetylated corn stover cell wall (Fig. 3b, c). This result is an indication that the cellulose content in the cell wall is not affected by the xylanase treatments used for these samples.

In contrast to the cellulose and lignin bands, the four xylan-sensitive bands at 920,1007, 1219, and $1471 \mathrm{~cm}^{-1}$ exhibit a dramatic and consistent reduction for all four of the xylan-removed cell walls samples (Fig. 4). The changes in the spectra of the xylan-removed cell walls are significantly greater than experimental error, indicating that those Raman bands are indeed associated with xylan removal.

\section{Xylan-specific Raman bands for in situ xylan imaging by SRS microscopy}

The four xylan-specific Raman bands were also validated by SRS microscopy and tested for the possibility of in situ imaging of xylan in chemically pretreated plant cell walls. Native, untreated corn stover cell wall samples were organosolv-pretreated to remove $55-70 \%$ of the 


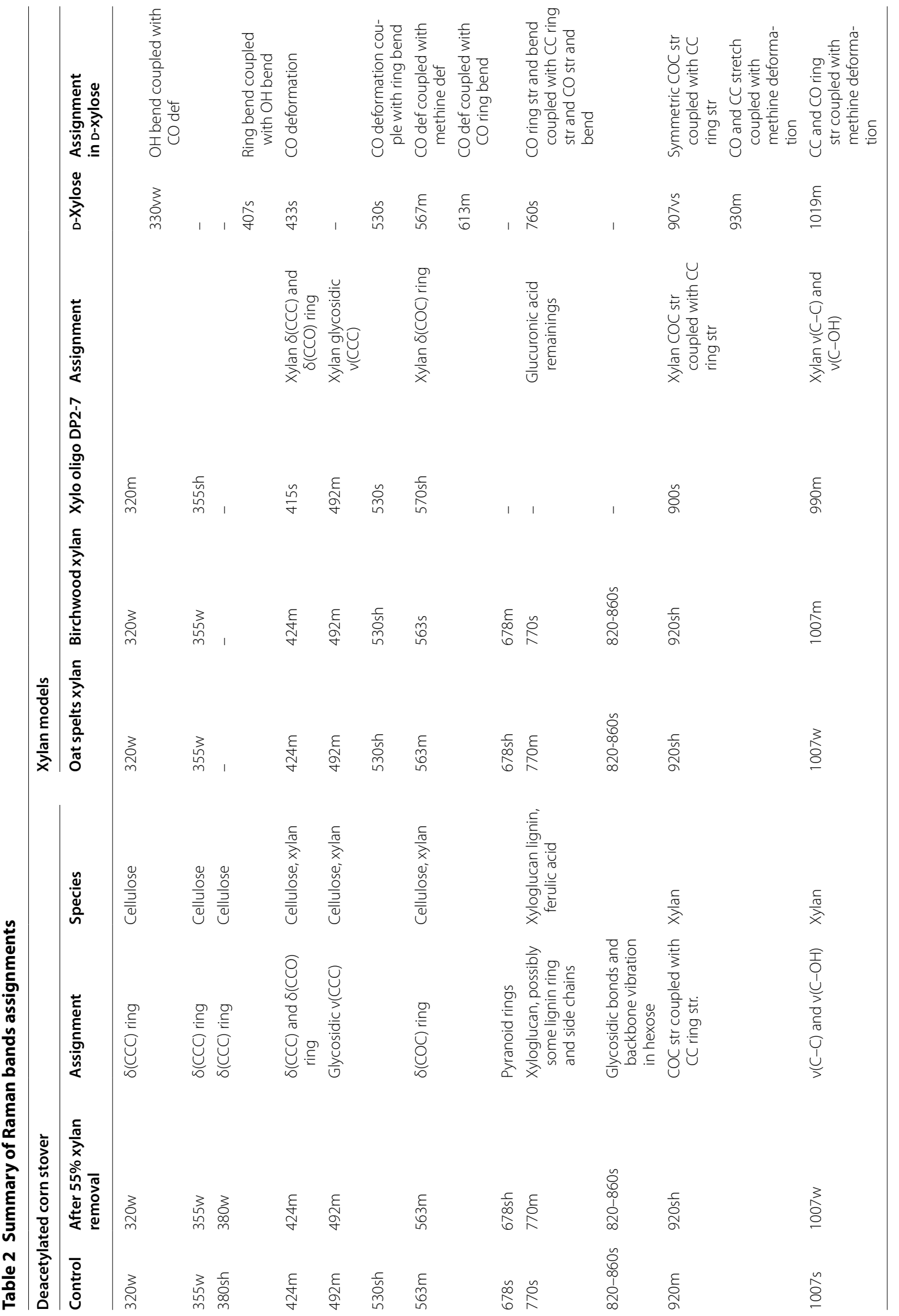




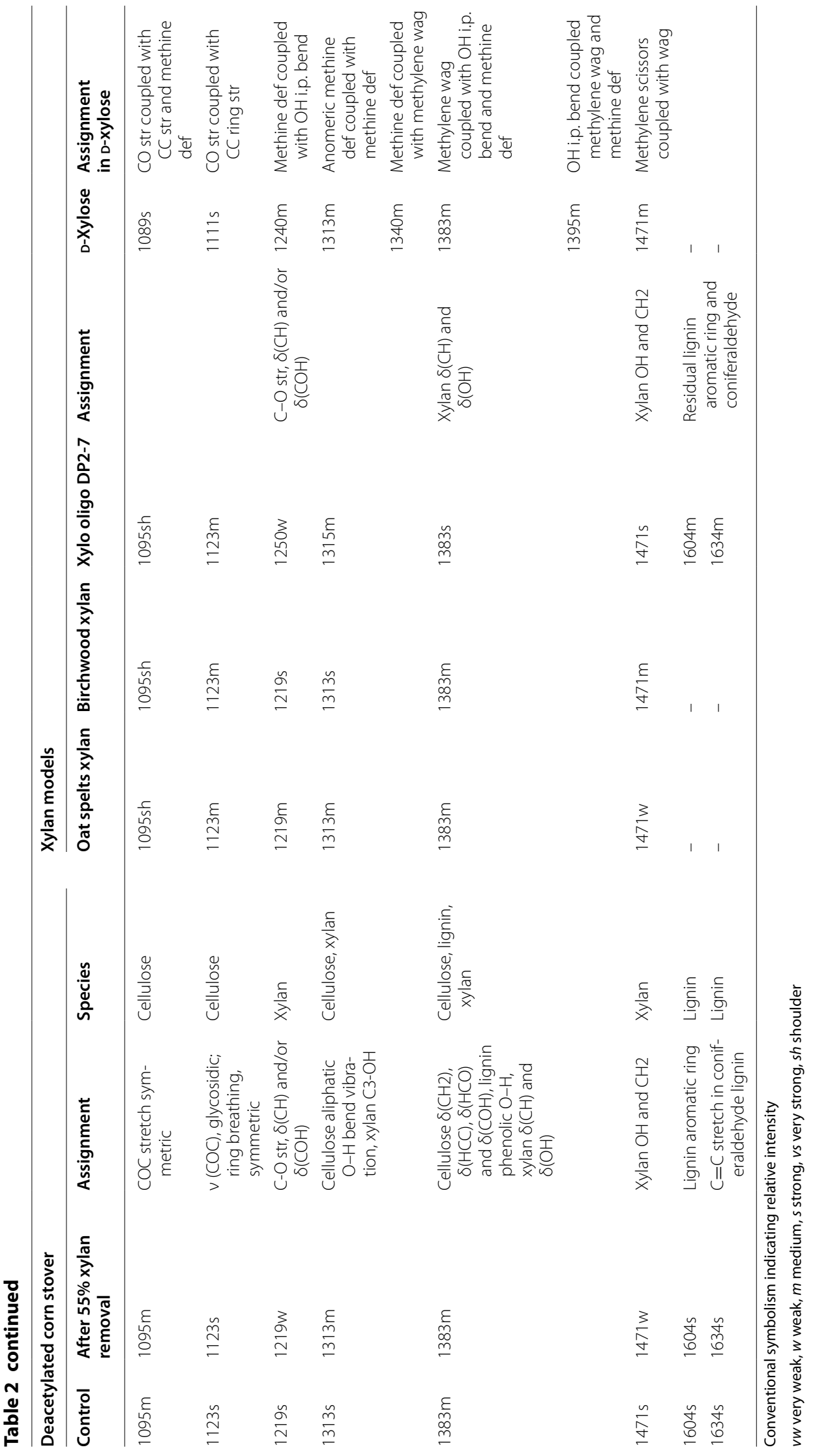


cell wall xylan (Additional file 1: Table S3, S4). Figure 5 compares the SRS images of two different types of cell walls, i.e., the vascular bundle cell wall and the parenchyma cell wall of the control and the xylan-reduced cell wall sample. When the relative cell wall xylan content was reduced from $100 \%$ to $~ 30$ to $45 \%$ in the organosolvpretreated cell walls, SRS signals from all four xylan frequencies also dropped. This correlation confirms that those Raman frequencies are specific to xylan content. Figure 5 also shows that the 1471 and $1219 \mathrm{~cm}^{-1}$ bands appear to have stronger SRS signals. Therefore, the SRS bands at 1471 and $1219 \mathrm{~cm}^{-1}$, especially the band at $1471 \mathrm{~cm}^{-1}$, might be more useful for imaging cell wall chemical details.

\section{In situ tracking of cell wall xylan during enzymatic digestion}

We demonstrated the capability of SRS to in situ image xylan in cell walls. Xylan, cellulose, and lignin were imaged by SRS for the same cell wall region following xylanase digestion. Figure 6 shows the distribution of lignin $\left(1600 \mathrm{~cm}^{-1}\right)$, cellulose $\left(1100 \mathrm{~cm}^{-1}\right)$, and xylan $\left(1471 \mathrm{~cm}^{-1}\right)$ in the same cell walls, before and after xylanase treatment. As shown in bright-field images, xylan digestion did not introduce significant cell wall damage (Fig. 6a1, 1'). Lignin distribution was not affected by the xylanase digestion as can be seen in both of the lignin distribution images (Fig. 6a2, 2'); as well as in the comparison of overall image intensities (Fig. 6b) which shows almost no change before and after xylanase digestion. Cellulose Raman images show only a slight change (Fig. 6a3, 3'). In contrast to lignin and cellulose Raman channels, dramatic intensity drop was observed in the xylan channel (Fig. 6a4, 4'). Importantly, besides significant reduction in the SRS signal, xylan distribution in cell walls was also altered by enzymatic digestion, often taking on punctate type morphology (arrow, Fig. 6). Zoomed-in xylan images of two representative areas in the vascular bundle region show significant xylan distribution changes due to the enzymatic digestion.

More striking xylanases-induced change in xylan distribution can be revealed by the in situ 3D SRS imaging of xylan in the same cell wall region following xylanases digestion. Figure 7 compares the 3D reconstructions of xylan's SRS signal at $1471 \mathrm{~cm}^{-1}$ before and after xylanases digestion. Xylan concentration as reflected by its SRS signal intensity clearly diminishes from cell lumen towards cell corner, whereas the remaining xylan is more located at cell corners. This 3D imaging technique could be useful for tracking xylan change under more complicate chemical/biological treatment conditions.

\section{Conclusions}

We report the identification of xylan-specific Raman bands using xylanases to specifically remove xylan from the polymer matrix of deacetylated corn stover cell walls. We further used SRS microscopic imaging to verify these xylan-specific Raman band assignments using organosolvpretreated native corn stover, which confirmed that these Raman bands are closely associated with the xylan content. Using the highest sensitivity xylan band as an example, we demonstrated that xylan can be resolved from cellulose and lignin in situ using enzymatic digestion and label-free SRS microscopy in both 2D and 3D. We believe that this novel approach can be used to map xylan in plant cell walls and that this ability will enhance our understanding of the role played by xylan in cell wall biosynthesis and deconstruction.

\section{Methods}

\section{Deacetylated corn stover}

The control corn stover was deacetylated and disc refined as previously described [63], to remove approximately $80 \%$ of the acetyl groups and improve xylanase digestion without significantly altering the cellulose, xylan, and lignin content. In brief, dry native corn stover was added to a dilute $0.1 \mathrm{M}$ sodium hydroxide to make the final $8 \%$

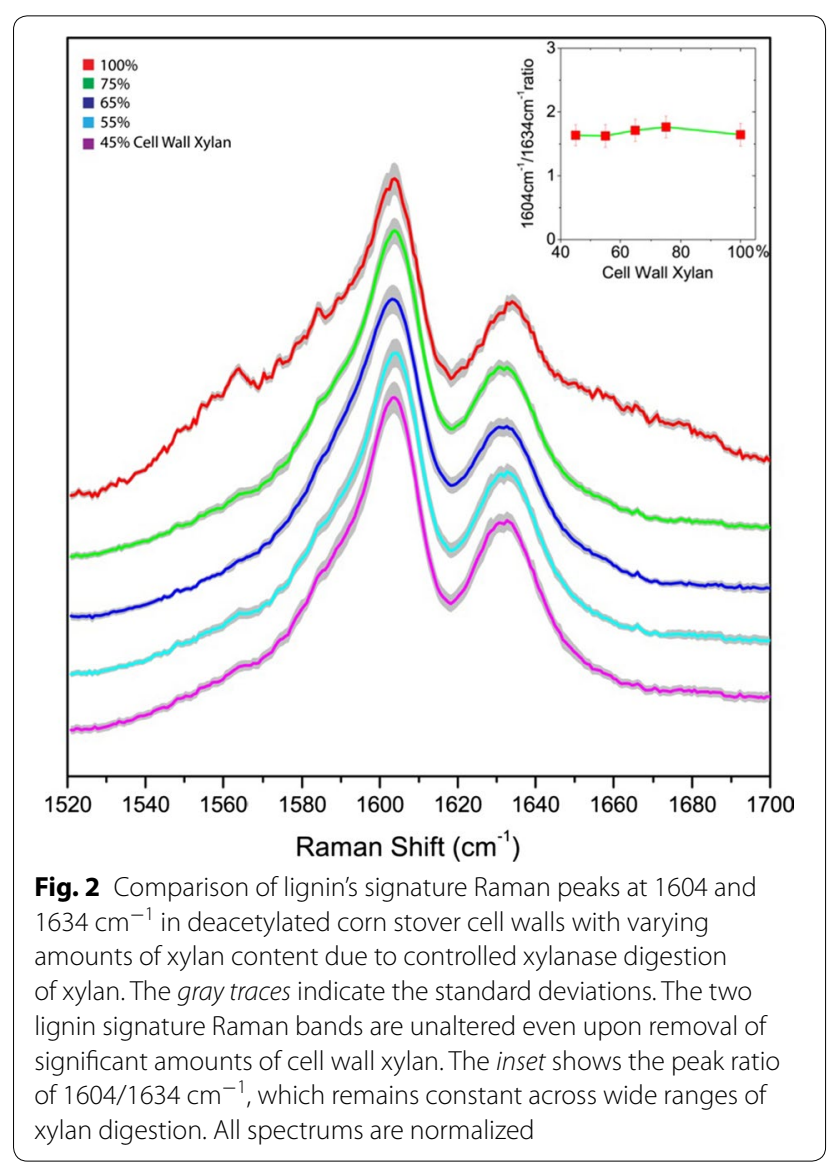


(w/w) total solids slurry. The slurry was heated to $80{ }^{\circ} \mathrm{C}$ for $2 \mathrm{~h}$, then drained, extensively washed and dried using a continuous screw press. The solids fraction was further milled with a commercial scale disc refining facility at the Andritz pilot plant and R\&D laboratory in Springfield (Ohio, United States).

Deacetylated corn stover sections were prepared by deacetylation of corn stover rind sticks $(\sim 1 \mathrm{~cm}$ long) using $0.1 \mathrm{M}$ hydroxide at $75^{\circ} \mathrm{C}$. Deacetylated rind sticks were rinsed extensively until $\mathrm{pH} \sim 7$ was attained and then transversely sectioned into $50-\mu \mathrm{m}$ slices with a rotary microtome (RM2235, Leica).

\section{Xylan model compounds}

Oat spelts xylan (X-0627), birchwood xylan (X-0502), and D-xylose (58-86-6, >99\%) were from Sigma-Aldrich, Missouri, United States. Xylo-oligosaccharides with degree of polymerization ranging from two to seven were from Cascade Analytical Reagents \& Biochemical, CAS 901463-5. The chemical compositional analysis for xylan model compounds was done by NREL laboratory analytical procedures [64]. Basically, a strong sulfuric acid solution was used for primary hydrolysis of the sample, followed by dilution with water and a secondary high-temperature hydrolysis step. This procedure hydrolyzes the carbohydrate fraction to soluble monosaccharides, leaving a lignin-rich residue to be vacuum filtered and measured gravimetrically. The sugars in the hydrolysate solution were measured as monomers to determine the carbohydrate fraction of the sample. Spelts xylan also contains 3-4\% glucuronic acids as part of xylan aside from the above NREL chemical compositional results. Birchwood xylan contains about $10-12 \%$ glucuronic acid as part of xylan.

\section{Enzymatic digestion of deacetylated corn stover to partially remove xylan from cell walls}

The deacetylated corn stover solids were washed with $20 \mathrm{mM}$ sodium acetate and $100 \mathrm{mM}$ sodium chloride buffer ( $\mathrm{pH} 4.8$ ) solution. The commercial enzyme product (Multifect ${ }^{\circledR}$ Xylanase from DuPont ${ }^{\mathrm{TM}}$ Genencor ${ }^{\circledR}$, Palo Alto, California, United States) was desalted in $10 \mathrm{~mL}$ aliquots using two serial HiPrep 26/10 desalting columns (GE Life Sciences, Piscataway NJ) equilibrated in $20 \mathrm{mM}$ sodium acetate buffer $(\mathrm{pH} 4.8)$ with $100 \mathrm{mM}$ sodium chloride. Protein containing fractions were pooled and protein concentration determined using the $\mathrm{BCA}$
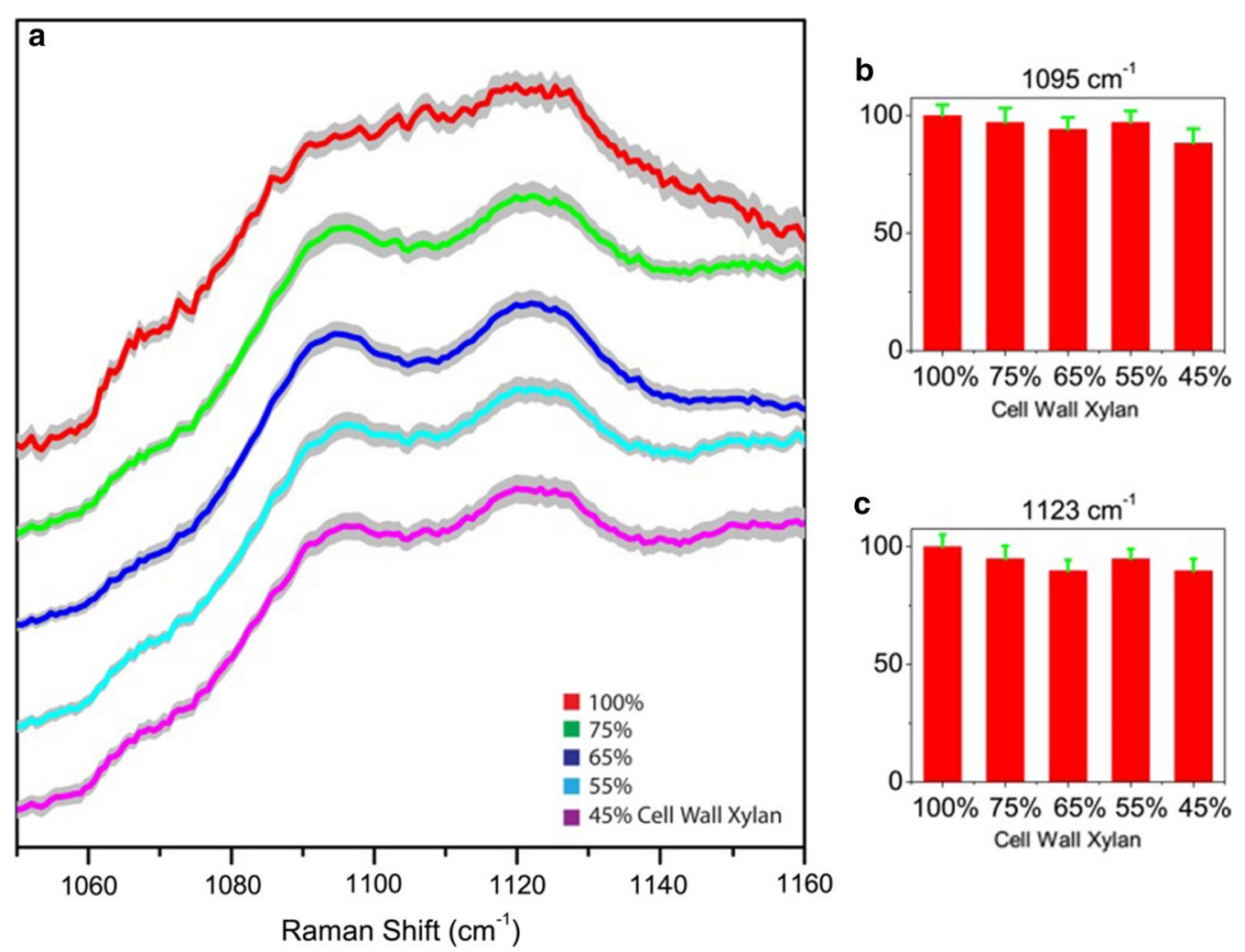

Fig. 3 Comparison of cellulose's signature Raman peaks at 1095 and $1123 \mathrm{~cm}^{-1}$ in deacetylated corn stover cell walls with varying amounts of xylan content due to controlled xylanase digestion of xylan. a Raman spectra show little change. b, c The peak heights of 1095 and $1123 \mathrm{~cm}{ }^{-1}$ in cell walls remain constant with varying amounts of cell wall xylan content. All spectrums are normalized. The gray traces indicate the standard deviations 

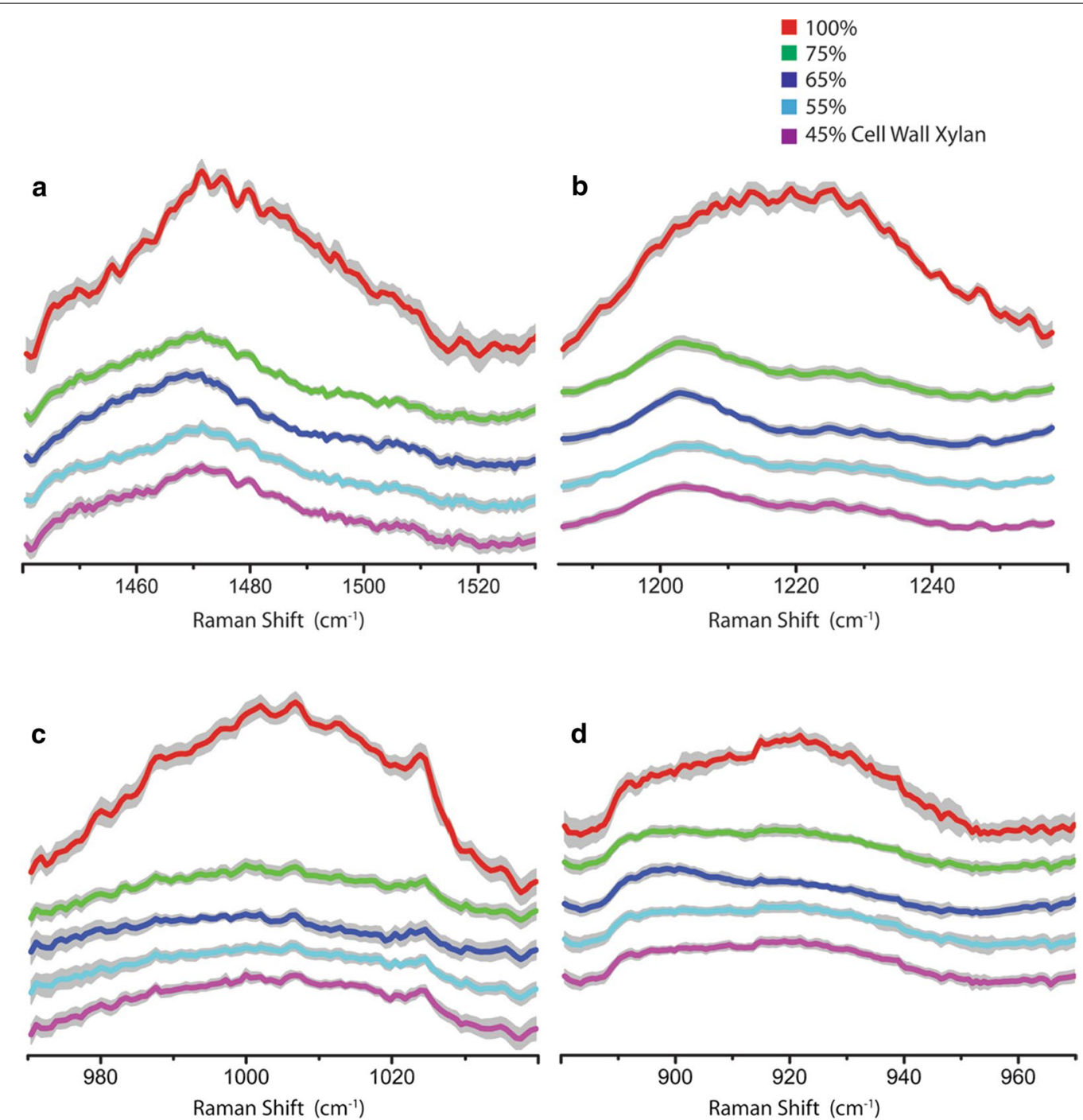

Fig. 4 Zoom-in comparisons of the xylan-specific Raman bands with varying amounts of xylan content due to controlled xylanase digestion of xylan. a $1471 \mathrm{~cm}^{-1}\left(x y l a n \mathrm{OH}\right.$ and $\left.\mathrm{CH}_{2}\right), \mathbf{b} 1219 \mathrm{~cm}^{-1}(x y l a n \mathrm{C}-\mathrm{O} \mathrm{str}, \delta(\mathrm{CH}), \delta(\mathrm{COH})), \mathbf{c} 1007 \mathrm{~cm}^{-1}\left(\right.$ xylan v(C-C) and v(C-OH)) and d $920 \mathrm{~cm}^{-1}(\mathrm{xylan}$ COC str coupled with CC ring str) in deacetylated corn stover cell wall with varying amounts of xylan content due to controlled xylanase digestion of xylan. The gray traces indicate the standard deviations. All spectrums are normalized

protein assay (Pierce Rockford, IL). Enzyme samples were desalted less than 2 days before use, with fresh material being generated for each experiment as desalted commercial enzymes tend to degrade and precipitate within a few days. The enzyme solution was added to same buffer solution containing deacetylated corn stover solids at $1 \%$ with enzyme loading at $3.6-58 \mathrm{mg} / \mathrm{g}$ xylan. Enzymatic digestions were performed in $2.5 \mathrm{~mL}$ shaker tubes in a shaking incubator at $45{ }^{\circ} \mathrm{C}$ and $150 \mathrm{rpm}$ for up to $40 \mathrm{~h}$.

\section{Organosolv treatment of native corn stover}

Organosolv treatment of native corn stover was performed following the same experimental procedure published previously [65]. The solution for organosolv treatment contained methyl isobutyl ketone (MIBK), acetone and water in the following ratio: MIBK:acetone:water = 11:44:44 (g:g:g, $100 \mathrm{~mL}$ ). The sulfuric acid concentration remained at $1.2 \mathrm{wt} \%$. After $2 \mathrm{~min}$ at $160{ }^{\circ} \mathrm{C}, 55 \%$ of the cell wall xylan was solubilized (45\% remaining). After $10 \mathrm{~min}, 70 \%$ of cell wall xylan was solubilized (30\% remaining). The xylan removal was measured according to the same experimental procedure published previously [65]. Basically, it was calculated by comparing the total amount of xylan (from compositional analysis of sample prior treatment) and the amount of sugar monomers in supernatant after organosolv treatment. 

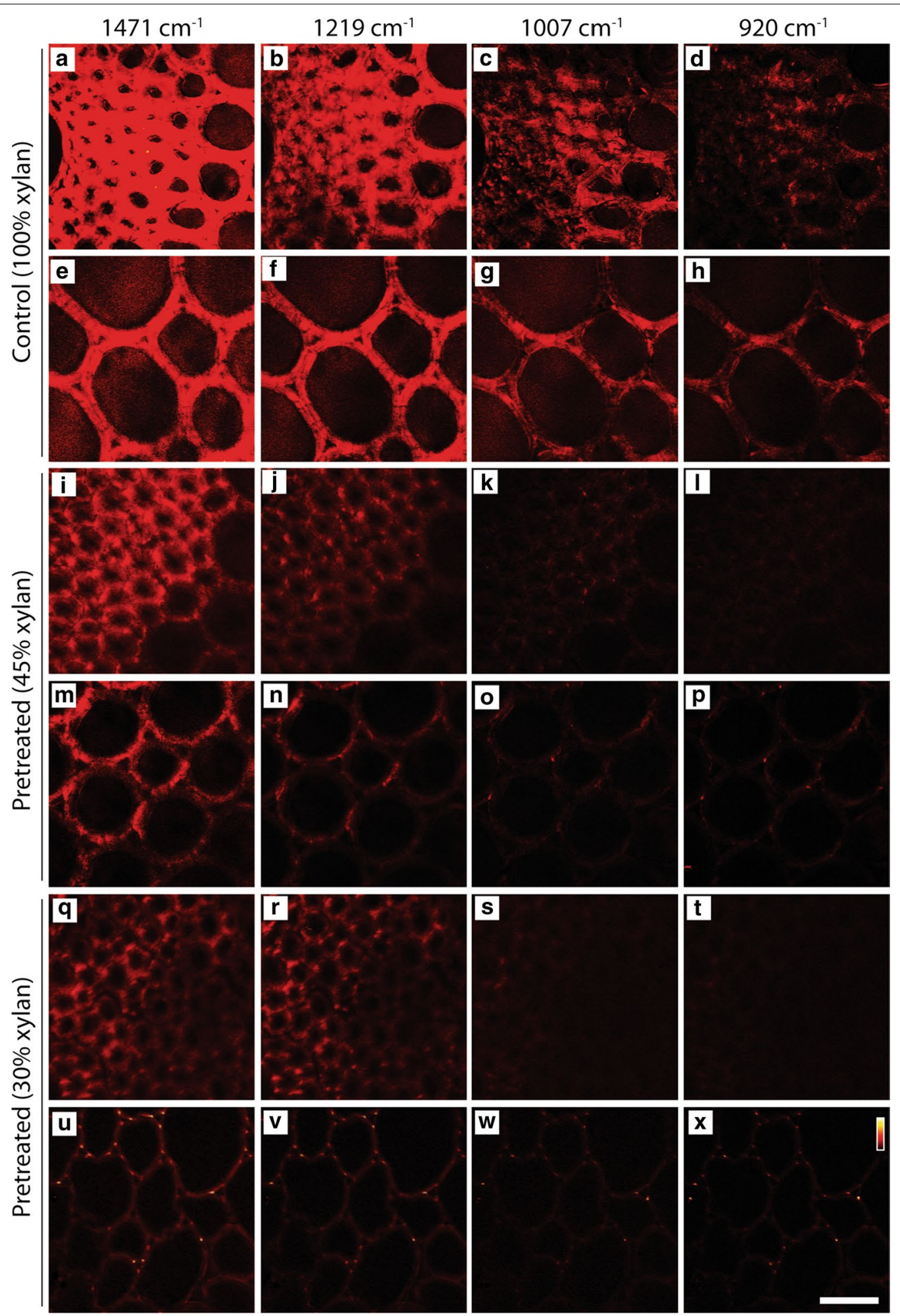

Fig. 5 Comparison of SRS images of xylan in the native, untreated corn stover (control) and organosolv-pretreated corn stover cell walls. Two types of cell walls are compared: secondary cell walls in the vascular bundle $(\mathbf{a}-\mathbf{d}, \mathbf{i}-\mathbf{I}, \mathbf{q}-\mathbf{t})$ and parenchyma cell walls $(\mathbf{e}-\mathbf{h}, \mathbf{m}-\mathbf{p}, \mathbf{u}-\mathbf{x})$. Scale bar $=30 \mu \mathrm{m}$ 


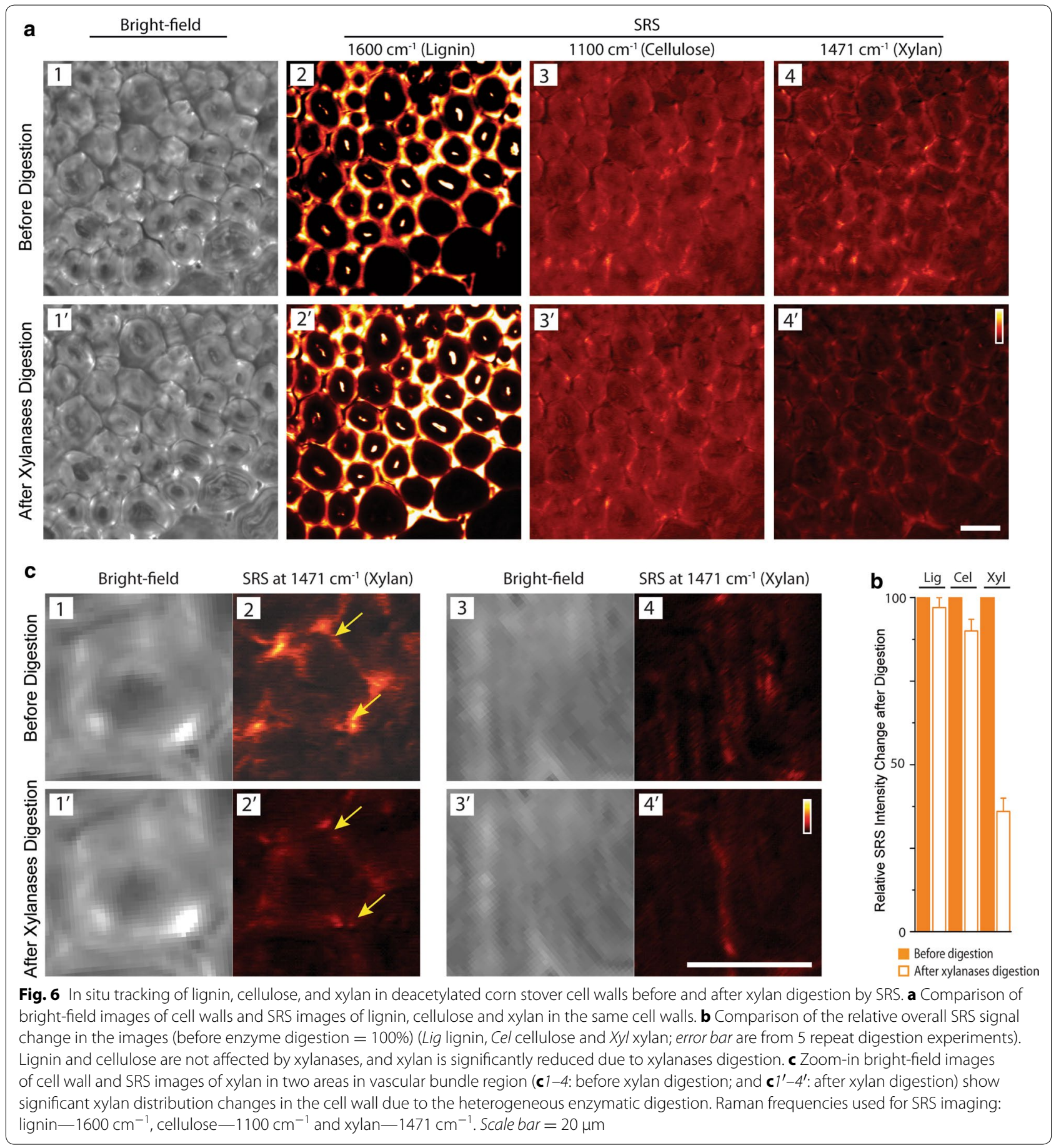

\section{Raman spectroscopic analysis}

All Raman spectra were acquired on a LabRam HR800 confocal Raman system (Horiba Jobin-Yvon, Edison, New Jersey, United States) equipped with an Olympus BX41 microscope and a $785 \mathrm{~nm}$ diode laser source. Sample powder was placed on a glass cover slide for measurement. The excitation beam was focused above the sample through a $40 \mathrm{X}$ objective lens (Olympus, UPlanSApo, 0.95 NA). The Raman scattering light from the sample was collected by the same objective lens. Before each spectrum acquisition, the sample was photo-bleached for $30 \mathrm{~min}$ to effectively reduce the 


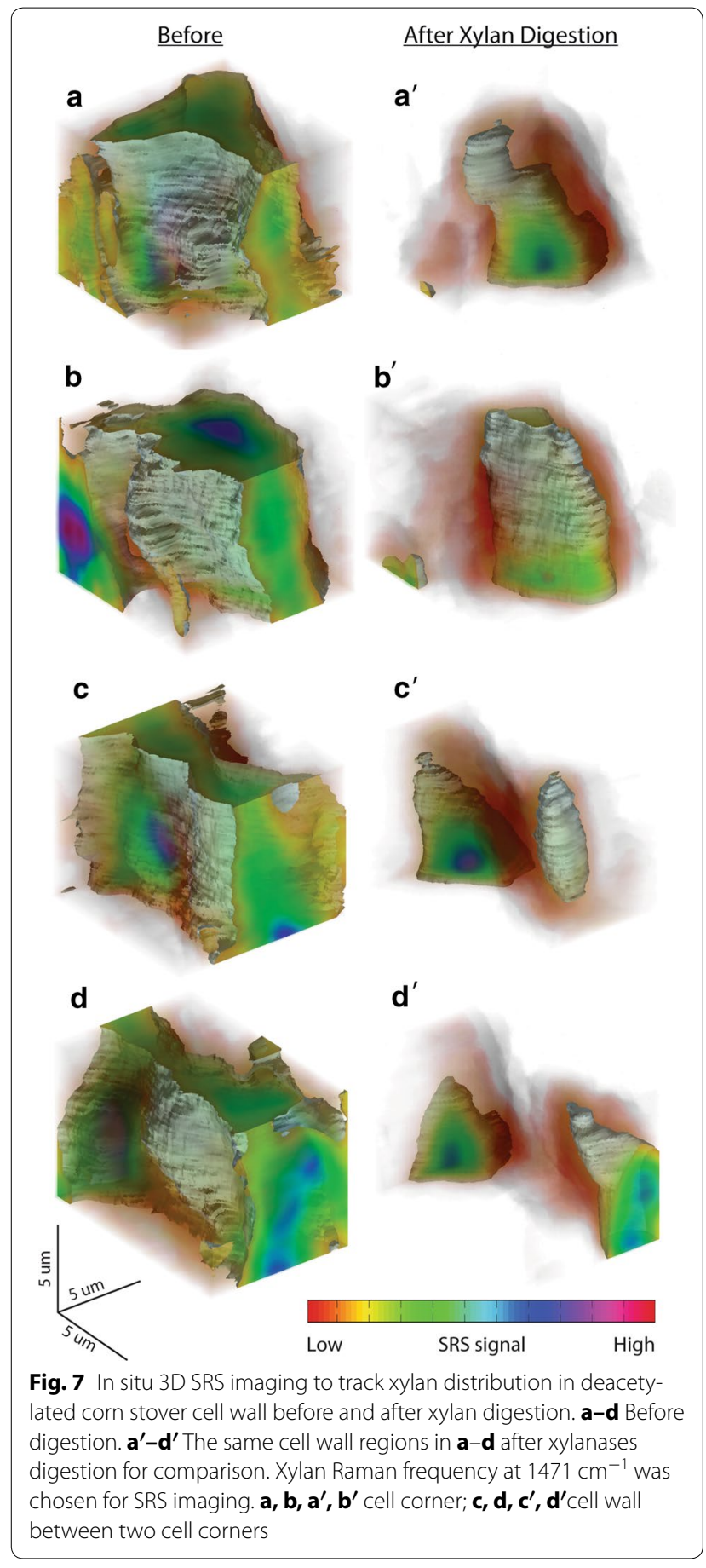

fluorescence background. This is indicated as the baseline shift between two adjacent spectrum scans, which was less than $10 \%$. With fluorescence background reduced, long integration times (usually $200 \mathrm{~s}$ ) were used so that the maximum Raman signal intensity is about $\sim 80 \%$ of the full dynamic range of the CCD detector. For each sample, more than 30 times accumulations were acquired to enhance the signal-to-noise ratio. Since in confocal Raman microscopy, the sampling volume is small and to minimize sampling error, more than 30 samples were measured for the each condition.

\section{SRS imaging}

The SRS imaging was conducted on the same SRS microscope as described previously [25]. In brief, a high-power Nd:YO4 oscillator (HighQ picoTRAIN, Spectra-Physics) producing 7 ps pulse trains at $1064 \mathrm{~nm}(15 \mathrm{~W} \max )$ and $532 \mathrm{~nm}(9 \mathrm{~W} \max )$ was used. $2 \mathrm{~W}$ of the $1064 \mathrm{~nm}$ light was used as the Stokes beam. The $532 \mathrm{~nm}$ beam was directed to pump an optic parametric oscillator (Levante Emerald, APE GmbH, Germany) to produce 6 ps tunable wavelength pulse train as the pump beam. The wavelength of the pump beam was adjusted for the selected Raman frequency. For example, it was tuned to $909.2 \mathrm{~nm}$ for lignin's resonance frequency at $1600 \mathrm{~cm}^{-1}$. The Stokes beam was intensity-modulated by an acoustic optic modulator (3080-122, Crystal Technology) at $10 \mathrm{MHz}$ with $80 \%$ modulation depth, and then combined with the pump beams by a long-pass beam combiner (1064dcrb, Chroma). The two beams were routed to a custom modified mirror-scanning microscope system (BX62WI/FV300, Olympus) attached with an Olympus inverted microscope. Typical laser power at the sample plane was $80 \mathrm{~mW}$ for each beam, and this allowed for continuous imaging without causing any noticeable photo-damage. The light transmitted through the sample was collected by a high numeric aperture condenser (1.45 NA O, Nikon), and filtered by an optical filter (CARS980/220, Chroma) to block the Stokes beam completely so that only amplitude modulation on the pump beams due to the SRS process was detected. The pump beam intensity was detected by a large-area silicon PIN photodiode (FDS1010, Thorlabs) back-biased at $70 \mathrm{~V}$. A lock-in amplifier (SR844, Stanford Research Systems) was used to detect the intensity change in the pump beam. 3D SRS imaging was performed by collect a stack of images along $\mathrm{Z}$ axis and the $3 \mathrm{D}$ rendering of the image stack was processed in Matlab.

\section{Xylanase digestion of deacetylated corn stover transverse sections}

An incubation chamber was constructed by two pieces of \#1 glass microscope coverslips sandwiched by a silicon separator (Grace Bio-Labs, Oregon, United States). One slice of the $50-\mu \mathrm{m}$ deacetylated corn stover slice was immersed in $125 \mu \mathrm{L} 20 \mathrm{mM}$ sodium acetate and $100 \mathrm{mM}$ sodium chloride buffer ( $\mathrm{pH} 4.8)$ solution containing Multifect ${ }^{\circledR}$ Xylanase (DuPont ${ }^{\mathrm{TM}}$ Genencor $^{\circledR}$, Palo 


\begin{abstract}
Alto, California, United States). The enzyme loading was approximately $93 \mathrm{mg} / \mathrm{g}$ xylan. The chamber was incubated at $45^{\circ} \mathrm{C}$ for $40 \mathrm{~h}$ for enzymatic digestion.
\end{abstract}

\section{Additional file}

Additional file 1: Figure S1. Basic chemical units of cellulose and xylan, and the two most common ordered cellulose structures. Table S1. Chemical compositional analysis of sugar content in the supernatant from the xylanase digested deacetylated corn stover cell wall. Table S2. Extent of sugars hydrolyzed from xylanase digestion of deacetylated corn stover. Table S3. Chemical compositional analysis of the supernatants from organosolv pretreated corn stover (compound per biomass). Table S4. Percentage of xylose and lignin dissolved from organosolv pretreated corn stover. Figure S2. SRS images of lignin, cellulose and xylan distribution in deacetylated and disc refined corn stover fragments before and after cell wall xylan removal by xylanases. ESI References.

\section{Abbreviations}

SRS: stimulated Raman scattering; CARS: coherent anti-stokes Raman scattering.

\section{Authors' contributions}

YZ performed Raman spectroscopy and stimulated Raman spectroscopy measurements. JMY performed enzyme digestion experiments. AM performed deacetylation and organosolv treatments. MPT, TBV, and SRD provided corn stover and xylan models. YZ wrote the manuscript. YZ, MEH, JMY, AM, TBV, and SRD revised the manuscript. All authors read and approved the final manuscript.

\section{Author details}

${ }^{1}$ Biosciences Center, National Renewable Energy Laboratory, Golden, CO 80401, USA. ${ }^{2}$ National Bioenergy Center, National Renewable Energy Laboratory, Golden, CO 80401, USA. ${ }^{3}$ BioEnergy Science Center (BESC), Oak Ridge National Laboratory, PO Box 2008 MS6341, Oak Ridge, TN 37831, USA.

\section{Acknowledgements}

The authors thank Deborah Hyman and Justin Sluiter both from National Renewable Energy Laboratory for their chemical compositional analysis, and David K. Johnson from National Renewable Energy Laboratory for his helpful discussion. The authors also thank Debra Mohnen from the Complex Carbohydrate Research Center (CCRC) for her valuable discussions regarding the experimental protocols and conclusions.

\section{Competing interests}

The authors declare that they have no competing interests.

\section{Availability of supporting data}

The data supporting the results of this article are included in this published article and its supplementary information document.

\section{Funding}

The authors also acknowledge support from the BioEnergy Science Center (BESC), a DOE Bioenergy Research Center funded by the Office of Biological and Environmental Research (BER) in the DOE Office of Science.

Received: 10 August 2016 Accepted: 15 November 2016 Published online: 22 November 2016

\section{References}

1. Shekiro J, Kuhn EM, Selig MJ, Nagle NJ, Decker SR, Elander RT. Enzymatic Conversion of Xylan Residues from Dilute Acid-Pretreated Corn Stover. Appl Biochem Biotechnol. 2012;168(2):421-33. doi:10.1007/ s12010-012-9786-5.
2. Deutschmann R, Dekker RFH. From plant biomass to bio-based chemicals: latest developments in xylan research. Biotechnol Adv. 2012;30(6):1627-40. doi:10.1016/j.biotechadv.2012.07.001.

3. Mäkinen KK. The rocky road of xylitol to its clinical application. J Dent Res. 2000;79(6):1352-5

4. Barbosa AM, Dekker RF, Giese EC. Bioactive oligosaccharides: production, biological functions, and potential commercial applications. New York: Nova Science Publishers; 2010.

5. Chung YC, Hsu CK, Ko CY, Chan YC. Dietary intake of xylooligosaccharides improves the intestinal microbiota, fecal moisture, and $\mathrm{pH}$ value in the elderly. Nutr Res. 2007;27(12):756-61. doi:10.1016/j.nutres.2007.09.014.

6. Crittenden R, Karppinen S, Ojanen S, Tenkanen M, Fagerstrm R, Mtt J, et al. In vitro fermentation of cereal dietary fibre carbohydrates by probiotic and intestinal bacteria. J Sci Food Agric. 2002;82(8):781-9. doi:10.1002/ jsfa.1095.

7. Manisseri C, Gudipati M. Bioactive xylo-oligosaccharides from wheat bran soluble polysaccharides. LWT Food Science and Technol. 2010;43(3):42130. doi:10.1016/j.lwt.2009.09.004.

8. Ohbuchi T, Takahashi T, Azumi N, Sakaino M. Structual analysis of neutral and acidic xylooligosaccharides from hardwood kraft pulp, and their utilization by intestinal bacteria in vitro. Biosci Biotechnol Biochem. 2009;73(9):2070-6. doi:10.1271/bbb.90260.

9. Pan X, Wu T, Zhang L, Cai L, Song Z. Influence of oligosaccharides on the growth and tolerance capacity of lactobacilli to simulated stress environment. Lett Appl Microbiol. 2009;48(3):362-7. doi:10.1111/j.1472-765X.2008.02539.x.

10. Rycroft CE, Jones MR, Gibson GR, Rastall RA. A comparative in vitro evaluation of the fermentation properties of prebiotic oligosaccharides. J Appl Microbiol. 2001;91(5):878-87. doi:10.1046/j.1365-2672.2001.01446.x.

11. Ng A, Greenshields RN, Waldron KW. Oxidative cross-linking of corn bran hemicellulose: formation of ferulic acid dehydrodimers. Carbohydr Res. 1997;303(4):459-62. doi:10.1016/S0008-6215(97)00193-6.

12. Aaltonen $\mathrm{O}$, Jauhiainen $\mathrm{O}$. The preparation of lignocellulosic aerogels from ionic liquid solutions. Carbohydr Polym. 2009;75(1):125-9. doi:10.1016/j.carbpol.2008.07.008.

13. Bouxin F, Marinkovic S, Bras JL, Estrine B. Direct conversion of xylan into alkyl pentosides. Carbohydr Res. 2010;345(17):2469-73. doi:10.1016/j. carres.2010.09.003.

14. Goksu El, Karamanlioglu M, Bakir U, Yilmaz L, Yilmazer U. Production and characterization of films from cotton stalk xylan. J Agric Food Chem. 2007;55(26):10685-91. doi:10.1021/jf071893i.

15. Šimkovic I, Mlynár J, Alföldi J. Modification of corn cob meal with quarternary ammonium groups. Carbohydr Polym. 1992;17(4):285-8.

16. Thiebaud S, Borredon M. Analysis of the liquid fraction after esterification of sawdust with octanoyl chloride-Production of esterified hemicelluloses. Bioresour Technol. 1998;63(2):139-45.

17. Ebringerová A, Sroková I, Talába P, Kačuráková M, Hromádková Z. Amphiphilic beechwood glucuronoxylan derivatives. J Appl Polym Sci. 1998;67(9):1523-30.

18. Buslov DK, Kaputski FN, Sushko NI, Torgashev VI, Solov'eva LV, Tsarenkov VM, et al. Infrared spectroscopic analysis of the structure of xylans. J Appl Spectrosc. 2009;76(6):801-5. doi:10.1007/s10812-010-9282-z.

19. Kumar R, Mago G, Balan V, Wyman CE. Physical and chemical characterizations of corn stover and poplar solids resulting from leading pretreatment technologies. Bioresour Technol. 2009;100(17):3948-62. doi:10.1016/j.biortech.2009.01.075.

20. Yin Y, Berglund L, Salmén L. Effect of steam treatment on the properties of wood cell walls. Biomacromolecules. 2011;12(1):194-202. doi:10.1021/ bm101144m.

21. Liu L, Ye XP, Womac AR, Sokhansanj S. Variability of biomass chemical composition and rapid analysis using FT-NIR techniques. Carbohydr Polym. 2010;81(4):820-9. doi:10.1016/j.carbpol.2010.03.058.

22. Philip Ye X, Liu L, Hayes D, Womac A, Hong K, Sokhansanj S. Fast classification and compositional analysis of cornstover fractions using Fourier transform near-infrared techniques. Bioresour Technol. 2008;99(15):732332. doi:10.1016/j.biortech.2007.12.063.

23. Kelley SS, Rials TG, Snell R, Groom LH, Sluiter A. Use of near infrared spectroscopy to measure the chemical and mechanical properties of solid wood. Wood Sci Technol. 2004;38(4):257-76. 
24. Monrroy M, Mendonça RT, Ruiz J, Baeza J, Freer J. Estimating glucan, xylan, and methylglucuronic acids in kraft pulps of Eucalyptus globulus using FT-NIR spectroscopy and multivariate analysis. J Wood Chem Technol. 2009;29(2):150-63. doi:10.1080/02773810902879017.

25. Zeng Y, Himmel ME, Ding S-Y. Coherent Raman Microscopy Analysis of Plant Cell Walls. In: Himmel ME, editor. Biomass Conversion. Methods in molecular biology. New York: Humana Press; 2012. p. 49-60.

26. Saar BG, Zeng YN, Freudiger CW, Liu YS, Himmel ME, Xie XS, et al. LabelFree, real-time monitoring of biomass processing with stimulated raman scattering microscopy. Angew Chem. 2010;49(32):5476-9. doi:10.1002/ anie.201000900.

27. Zeng Y, Saar B, Friedrich M, Chen F, Liu Y-S, Dixon R, et al. Imaging Lignin-Downregulated Alfalfa Using Coherent Anti-Stokes Raman Scattering Microscopy. Bioenerg Res. 2010;3(3):272-7. doi:10.1007/ s12155-010-9079-1.

28. Zeng Y, Zhao S, Yang S, Ding S-Y. Lignin plays a negative role in the biochemical process for producing lignocellulosic biofuels. Curr Opin Biotechnol. 2014;27:38-45. doi:10.1016/j.copbio.2013.09.008.

29. Zeng $Y$, Zhao S, Wei H, Tucker M, Himmel M, Mosier N, et al. In situ micro-spectroscopic investigation of lignin in poplar cell walls pretreated by maleic acid. Biotechnol Biofuels. 2015;8(1):1-12. doi:10.1186/ s13068-015-0312-1.

30. Gierlinger N, Schwanninger M. Chemical Imaging of Poplar Wood Cell Walls by Confocal Raman Microscopy. Plant Physiol. 2006;140(4):1246-54. doi:10.1104/pp.105.066993.

31. Gierlinger N, Keplinger T, Harrington M. Imaging of plant cell walls by confocal Raman microscopy. Nat Protocols. 2012;7(9):1694-708. http://www.nature.com/nprot/journal/v7/n9/abs/nprot.2012.092. html\#supplementary-information.

32. Gierlinger N, Keplinger T, Harrington M, Schwanninger M. Raman imaging of lignocellulosic feedstock. In: van de Ven T, Kadla J, editors. Cellulosebiomass conversion. Croatia: InTech; 2013.

33. Sun L, Simmons BA, Singh S. Understanding tissue specific compositions of bioenergy feedstocks through hyperspectral Raman imaging. Biotechnol Bioeng. 2011;108(2):286-95. doi:10.1002/bit.22931.

34. Gardiner ES, Sarko A. Packing analysis of carbohydrates and polysaccharides. 16. The crystal structures of celluloses IVI and IVII. Can J Chem. 1985;63(1):173-80.

35. Gregory ACE, O'Connell AP, Bolwell GP. Xylans. Biotechnol Genet Eng Rev. 1998;15(1):439-56. doi:10.1080/02648725.1998.10647965.

36. James HW, Rajai HA. Raman spectra of celluloses. The structures of cellulose. ACS Symposium series, vol. 340. Washington: ACS Publications; 1987. p. 151-68.

37. Wiley JH, Atalla RH. Band assignments in the Raman spectra of celluloses. Carbohydr Res. 1987;160:113-29.

38. Schenzel K, Fischer S. NIR FT Raman spectroscopy-a rapid analytical tool for detecting the transformation of cellulose polymorphs. Cellulose. 2001;8(1):49-57. doi:10.1023/a:1016616920539.

39. Agarwal UP, Ralph SA. FT-Raman spectroscopy of wood: identifying contributions of lignin and carbohydrate polymers in the spectrum of black spruce (Picea mariana). Appl Spectrosc. 1997;51(11):1648-55.

40. Kačuráková M, Wellner N, Ebringerová A, Hromádková Z, Wilson RH, Belton PS. Characterisation of xylan-type polysaccharides and associated cell wall components by FT-IR and FT-Raman spectroscopies. Food Hydrocolloids. 1999:13(1):35-41. doi:10.1016/S0268-005X(98)00067-8.

41. Chylińska M, Szymańska-Chargot M, Zdunek A. Imaging of polysaccharides in the tomato cell wall with Raman microspectroscopy. Plant Methods. 2014;10:14. doi:10.1186/1746-4811-10-14.

42. Himmelsbach DS, Khahili S, Akin DE. Near-infrared-Fourier-transformRaman microspectroscopic imaging of flax stems. Vib Spectrosc. 1999;19(2):361-7. doi:10.1016/S0924-2031(98)00065-4.

43. Chu L-Q, Masyuko R, Sweedler JV, Bohn PW. Base-induced delignification of miscanthus $x$ giganteus studied by three-dimensional confocal raman imaging. Bioresour Technol. 2010;101(13):4919-25. doi:10.1016/j. biortech.2009.10.096.

44. Carlson KP. A investigation of the vibrational spectra of the cellodextrins. Georgia Institute of Technology; 1979.
45. Edwards SL. An investigation of the vibrational spectra of the pentose sugars. Georgia Institute of Technology; 1976 (Doctoral Dissertation)

46. Mathlouthi M, Koenig JL. Vibrational spectra of carbohydrates. Adv Carbohydr Chem Biochem. 1986;44:7-89.

47. Szymańska-Chargot M, Chylińska M, Pieczywek PM, Rösch P, Schmitt M, Popp J, et al. Raman imaging of changes in the polysaccharides distribution in the cell wall during apple fruit development and senescence. Planta. 2016;243:935-45. doi:10.1007/s00425-015-2456-4.

48. Agarwal UP. An overview of Raman spectroscopy as applied to lignocelIulosic materials. In: Argyropoulos DS, editor. Advances in lignocellulosics characterization. Atlanta:TAPPI Press; 1999. p. 209-25.

49. Bansil R, Yannas IV, Stanley HE. Raman spectroscopy: a structural probe of glycosaminoglycans. Biochim Biophys Acta. 1978;541(4):535-42. doi:10.1016/0304-4165(78)90163-0.

50. Zhbankov RG, Andrianov VM, Marchewka MK. Fourier transform IR and Raman spectroscopy and structure of carbohydrates. J Mol Struct. 1997:436-437:637-54. doi:10.1016/s0022-2860(97)00141-5.

51. Wells HA Jr, Atalla RH. An investigation of the vibrational spectra of glucose, galactose and mannose. J Mol Struct. 1990;224:385-424. doi:10.1016/0022-2860(90)87031-r.

52. Engelsen SB, Nørgaard L. Comparative vibrational spectroscopy for determination of quality parameters in amidated pectins as evaluated by chemometrics. Carbohydr Polym. 1996;30(1):9-24. doi:10.1016/ s0144-8617(96)00068-9.

53. Heitner C, Dimmel D, Schmidt J. Lignin and lignans: advances in chemistry. Boca Raton: CRC Press; 2010.

54. Agarwal U. Raman imaging to investigate ultrastructure and composition of plant cell walls: distribution of lignin and cellulose in black spruce wood (Picea mariana). Planta. 2006;224(5):1141-53. doi:10.1007/ s00425-006-0295-Z

55. Yu P, Block H, Niu Z, Doiron K. Rapid characterization of molecular chemistry, nutrient make-up and microlocation of internal seed tissue. J Synchrotron Radiat. 2007;14(4):382-90. doi:10.1107/S0909049507014264.

56. Wetzel D, Eilert A, Pietrzak L, Miller S, Sweat J. Ultraspatially-resolved synchrotron infrared microspectroscopy of plant tissue in situ. Cell Mol Biol. 1998;44(1):145-68.

57. Budevska BO. Vibrational spectroscopy imaging of agricultural products. In: Griffiths PR, editor. Handbook of vibrational spectroscopy. New York: John Wiley \& Sons Ltd; 2006.

58. Himmelsbach DS, Akin DE. Near-infrared Fourier-transform Raman spectroscopy of flax (Linum usitatissimum L.) stems. J Agric Food Chem. 1998:46(3):991-8.

59. Lupoi JS, Smith EA. Characterization of woody and herbaceous biomasses lignin composition with $1064 \mathrm{~nm}$ dispersive multichannel Raman spectroscopy. Appl Spectrosc. 2012;66(8):903-10.

60. Agarwal UP, McSweeny JD, Ralph SA. FT-Raman investigation of milledwood lignins: softwood, hardwood, and chemically modified black spruce lignins. J Wood Chem Technol. 2011;31(4):324-44.

61. Hänninen T, Kontturi E, Vuorinen T. Distribution of lignin and its coniferyl alcohol and coniferyl aldehyde groups in Picea abies and Pinus sylvestris as observed by Raman imaging. Phytochemistry. 2011;72(14):1889-95.

62. Agarwal UP, Ralph SA. Determination of ethylenic residues in wood and TMP of spruce by FT-Raman spectroscopy. Holzforschung. 2008;62(6):667-75.

63. Chen X, Shekiro J, Pschorn T, Sabourin M, Tao L, Elander R, et al. A highly efficient dilute alkali deacetylation and mechanical (disc) refining process for the conversion of renewable biomass to lower cost sugars. Biotechnol Biofuels. 2014;7(1):1-12.

64. Sluiter JB, Ruiz RO, Scarlata CJ, Sluiter AD, Templeton DW. Compositional Analysis of Lignocellulosic Feedstocks. Review and Description of Methods. J Agric Food Chem. 2010;58(16):9043-53. doi:10.1021/jf1008023.

65. Mittal A, Vinzant TB, Brunecky R, Black SK, Pilath HM, Himmel ME, et al. Investigation of the role of lignin in biphasic xylan hydrolysis during dilute acid and organosolv pretreatment of corn stover. Green Chem. 2015;17(3):1546-58. doi:10.1039/c4gc02258k. 